\title{
Automatic Calibration of the SHETRAN Hydrological Modelling System Using MSCE
}

\author{
Rong Zhang • Celso A. G. Santos • Madalena Moreira • Paula K. M. M. Freire • \\ João Corte-Real
}

Received: 1 May 2012 / Accepted: 16 June 2013

(C) Springer Science+Business Media Dordrecht 2013

\begin{abstract}
Automatic calibration is preferred because it provides an objective and extensive searching in the feasible parameter space. In this study, the Modified Shuffled Complex Evolution (MSCE) optimization algorithm is applied to automatically calibrate the physically-based spatially-distributed hydrological model SHETRAN in the $705-\mathrm{km}^{2}$ semi-arid Cobres basin in southern Portugal, with a spatial resolution of $2 \mathrm{~km}$ and a temporal resolution of $1 \mathrm{~h}$. Twenty-two parameters are calibrated for the main types of land-use and soil. Nash-Sutcliffe Efficiency (NSE) is 0.86 for calibration and 0.74 for validation for basin outlet; NSE is respectively 0.65 and 0.82 for calibration, 0.69 and 0.63 for validation of internal gauging stations Albernoa and Entradas. As for storm events, NSE is 0.87 and 0.64 respectively for Storms No.1 (during the calibration period) and No.4 (during the validation period) at basin outlet; it is 0.69 and 0.65 for Storm No.4 respectively at Albernoa and
\end{abstract}

R. Zhang $(\bowtie) \cdot$ M. Moreira $\cdot$ J. Corte-Real

Institute of Mediterranean Agrarian and Environmental Sciences (ICAAM), Group Water, Soil and Climate, University of Évora, Núcleo da Mitra, Apartado 94, 7002-774 Évora, Portugal

e-mail: rzhang@uevora.pt

M. Moreira

e-mail: mmvmv@uevora.pt

J. Corte-Real

e-mail: jmcr@uevora.pt

C. A. G. Santos • P. K. M. M. Freire

Department of Civil and Environmental Engineering, Federal University of Paraíba, 58051-900 João Pessoa, Paraíba, Brazil

C. A. G. Santos

e-mail: celso@ct.ufpb.br

P. K. M. M. Freire

e-mail: pulkymm@gmail.com

J. Corte-Real

Department of Aeronautics and Transports, University Lusófona of Humanities and Technologies,

Research Unit in Aeronautical Sciences (UNICA), Lisbon, Portugal 